\title{
Classification and Processing Optimization of Barley Milk Production Using NIR Spectroscopy, Particle Size, and Total Dissolved Solids Analysis
}

\author{
Jasenka Gajdoš Kljusurić, Maja Benković, and Ingrid Bauman \\ Faculty of Food Technology and Biotechnology, University of Zagreb, Pierottijeva 6, 10000 Zagreb, Croatia \\ Correspondence should be addressed to Maja Benković; mbenkovic@pbf.hr
}

Received 19 March 2015; Revised 29 May 2015; Accepted 30 May 2015

Academic Editor: Ghada M. Hadad

Copyright (C) 2015 Jasenka Gajdoš Kljusurić et al. This is an open access article distributed under the Creative Commons Attribution License, which permits unrestricted use, distribution, and reproduction in any medium, provided the original work is properly cited.

Barley is a grain whose consumption has a significant nutritional benefit for human health as a very good source of dietary fibre, minerals, vitamins, and phenolic and phytic acids. Nowadays, it is more and more often used in the production of plant milk, which is used to replace cow milk in the diet by an increasing number of consumers. The aim of the study was to classify barley milk and determine the optimal processing conditions in barley milk production based on NIR spectra, particle size, and total dissolved solids analysis. Standard recipe for barley milk was used without added additives. Barley grain was ground and mixed in a blender for 15, 30, 45, and 60 seconds. The samples were filtered and particle size of the grains was determined by laser diffraction particle sizing. The plant milk was also analysed using near infrared spectroscopy (NIRS), in the range from 904 to $1699 \mathrm{~nm}$. Furthermore, conductivity of each sample was determined and microphotographs were taken in order to identify the structure of fat globules and particles in the barley milk. NIR spectra, particle size distribution, and conductivity results all point to 45 seconds as the optimal blending time, since further blending results in the saturation of the samples.

\section{Introduction}

Barley (Hordeum vulgare L.) has been one of the most important food grains since ancient times, which has been commonly cultivated due to its versatility, ability to adapt to unfavourable climate and soil conditions, and superior properties for the malting and brewing industry [1]. In recent times, about two-thirds of the barley crop has been used for feed, one-third for malting and about $2 \%$ for food directly [2]. As for food use, nutritional benefits of barley include high content of dietary fibers, minerals (molybdenum, manganese, selenium, copper, chromium, phosphorus, and magnesium), vitamins (vitamins B1, E, and niacin), and phenolic and phytic acids. Health benefits of barley include lowering blood cholesterol and glycaemic index, due to the presence of $\beta$-glucans [3]. It is also a rich source of tocols, including tocopherols and tocotrienols, which are known to reduce serum LDL cholesterol through their antioxidant action [2]. Barley food uses include pearled barley, grits, flakes, flour, bread, cakes, cookies, noodles, and extruded snack foods [4]. Recently, it is more often used in the production of plant milk.
Plant based milk substitutes are water soluble extracts of legumes, oil seeds, cereals, or pseudocereals that resemble cow's milk in appearance. Such milk is used to replace cow milk in the diet by an increasing number of consumers for medical reasons (e.g., lactose intolerance, cow's milk allergy) or as a lifestyle choice [5]. In comparison to bovine milk, the cereal and grain milks have no cholesterol or lactose, which makes them an attractive alternative to bovine milk for people conscious of their health and/or diet, vegetarians, and those who are lactose intolerant [6]. Plant based milk substitutes are manufactured by the extraction of plant material in water, removal of solids, and product formulation, followed by homogenisation and heat treatment. The resulting products are suspensions which contain plant material, oils, and hydrocolloids, if used [6,7]. Problem which can occur during production and storage of plant based milk is separation of proteins, oil droplets, or cellular fragments either by sedimentation, creaming, or syneresis.

Previous research has shown that phase separation, stability, and quality of emulsions, especially milk and milk 
products, can be successfully characterized by near infrared reflectance spectroscopy [8-10].

Near infrared region covers the range of electromagnetic spectrum between 780 and $2500 \mathrm{~nm}$. The basic principle in NIRS is that the examined sample is irradiated with NIR radiation and the reflected or transmitted radiation is recorded in the form of a spectrum [11]. NIRS is a fast and nondestructive analytical method so it is of potential easy application in industrial setting [12].

The aim of this study was to determine the optimal processing conditions for barley milk production, as well as the classification of produced barley milk based on the NIR spectrum, particle size, and conductivity.

\section{Materials and Methods}

2.1. Materials. Barley was obtained from the market as a product named "barley mash" that was produced, harvested, processed, and packed in year 2014, in Croatia. Abbreviations used for the samples are shown in the Abbreviation Section.

\subsection{Methods}

2.2.1. Sample Preparation. Barley $(60 \mathrm{~g})$ was soaked in $90 \mathrm{~mL}$ of water for 12 hours. Additional $135 \mathrm{~mL}$ of water was added to the soaked barley and blended for 15, 30, 45, and 60 seconds in a blender (Tefal Performa, France). The plant based milk (barley milk) was filtered through a gauze and separated from the spent barley grain. Samples of barley milk and spent barley grain (now in the emulsion form) were stored at $4^{\circ} \mathrm{C}$ until they were analysed.

2.2.2. NIRS. NIR analysis was conducted using the instrument Control Development, Inc. (South Bend, USA), NIR128-1.7-USB/6.25/50 $\mu \mathrm{m}$, with installed Control Development software Spec32, in the near infrared range from 904 to $1699 \mathrm{~nm}$, with the spectral resolution $6.25 \mu \mathrm{m}$. The instrument has a halogen light source (HL-2000) which was connected to the probe. Reflectance probe was used to illuminate the samples in a plastic vessel (maximal volume of $10 \mathrm{~mL}$ ) and placed in a holder to minimize the light from the environment. The probe was immersed in the samples. NIR spectroscopy was used as a nondestructive technique of sample measurement and the reflectance mode was used. Each absorbance spectrum was recorded in triplicate and the mean value was calculated. The first and second derivate NIR spectra were also obtained.

2.2.3. Particle Size Distribution. Particle size distribution was determined by a laser diffraction method. Mastersizer 2000 instrument coupled with a Hydro 2000S wet dispersion unit (Malvern Instruments, Worcestershire, United Kingdom) was used to analyse particle size of both milk and spent grain samples. Measurements were repeated three times per sample. Results are expressed as particle size distributions (by volume) and the following particle size parameters: median particle diameter (mass median diameter) $d(0.5)$, surface weighed mean (surface area moment mean diameter, Sauter diameter) $D[3,2]$, all expressed in $\mu \mathrm{m}$, and specific surface area $\left[\mathrm{m}^{2} \mathrm{~g}^{-1}\right]$.

2.2.4. Electrical Conductivity. Conductivity measurements and total dissolved solids (TDS) were monitored at room temperature using a TDS/conductivity meter type Oakton CON 200 (Oakton Instruments, Vernon Hills, USA).

2.2.5. Microscopy. Light microscopy was performed on the milk and spent grain samples in order to identify particle types and structures present in the samples. Samples were viewed by microscope (BTC Type LCD-35 Bresser (Springdale, USA)) at 400x magnification. "Blind" samples containing distilled water and sunflower oil emulsion mixed for $15,30,45$, and 60 seconds were also prepared and the oil droplets present in the blind samples were compared with the oil droplets in the barley samples, in order to identify particle types in the complex barley milk suspension.

2.2.6. Data Analysis. Average values with the corresponding standard deviation were calculated for all the measurements. Spectra were exported from the Spec32 software into the Statistica software v.8 (StatSoft, Tulsa, USA) for chemometric analysis. Principal component analysis (PCA) was used to investigate if it was possible to classify the samples, distinguish them (barley milk from barley spent and grain) just using the NIR spectra, and detect potential sample outliers [13]. Statistical significance was considered at $p<0.05$.

\section{Results and Discussion}

3.1. NIRS. Barley was soaked in water over night to reduce the phytic acids [14] for maximum digestion and make nutrients more available [15]. Water content can be seen in Figure 1 which presents the NIR absorbance spectra and its first derivatives. Each line (Figure 1(a)) represents the average spectra. For spectral features, strong absorption bands around 670, 740, 980, 1200, 1450, 1780, and $1930 \mathrm{~nm}$ [16] were reported, but the range of the NIR instrument used for analysis was not so wide $(904-1699 \mathrm{~nm})$ and, correspondingly, the specific ranges for observed samples that should be highlighted are around $980 \mathrm{~nm}, 1128-1196 \mathrm{~nm}$, and 1350 to 1693 with a specific peak at $1450 \mathrm{~nm}$.

Absorption bands in the range of 980 to $1450 \mathrm{~nm}$ were also observed, where the absorption at $980 \mathrm{~nm}$ was associated with the second overtone of $\mathrm{H}-\mathrm{O}-\mathrm{H}$ stretching modes of water; 1200 with the combination of second overtones of C$\mathrm{H}$ and $\mathrm{C}-\mathrm{H}_{2}$ stretching; and 1450 to the first overtone of $\mathrm{O}-\mathrm{H}$ stretching [17-19]. In all observed samples, the $\mathrm{H}-\mathrm{O}-$ $\mathrm{H}$ stretching modes of water in the range of $1380-1670 \mathrm{~nm}$ stood out in particular, with a spectra peak at $1450 \mathrm{~nm}$ and derivation peak at $1410 \mathrm{~nm}$, respectively.

NIR spectrum indicated higher values of the absorption units for samples which were blended for a shorter period of time. The highest absorbance units were observed for the sample blended for 15 seconds (Figure 1(a)) and this trend was also apparent in the first derivative spectra (Figure 1(b)). Samples blended for 45 and 60 seconds (milk and grain 


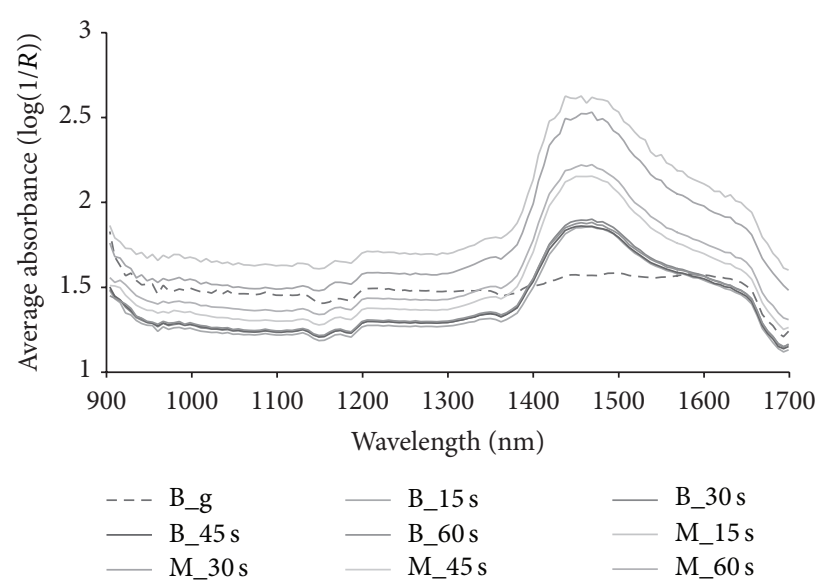

(a)

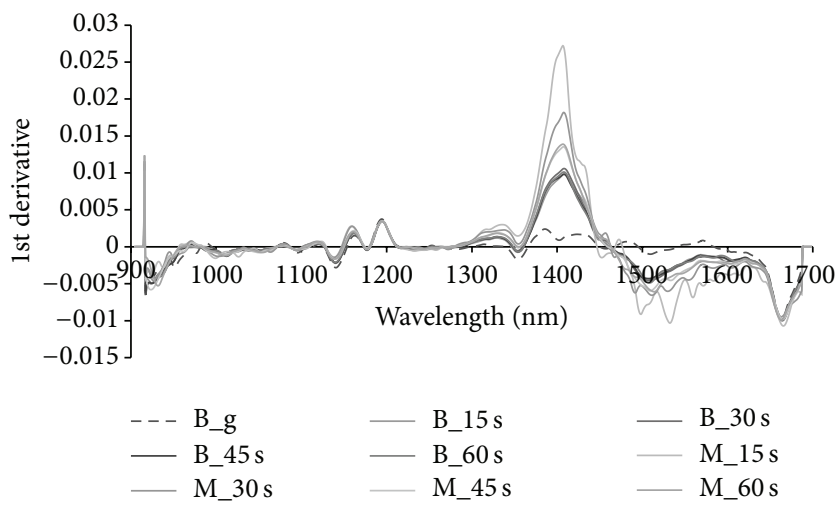

(b)

FIGURE 1: (a) NIR absorbance spectra and (b) first derivative of NIR spectra for barley grain (B_g), barley milk (M), and spent grain (B) after $15,30,45$, and 60 seconds of blending.

samples) were detected as the exceptions (Figures 1(a) and $1(\mathrm{~b})$ ). In order to determine what caused such behavior, conductivity, particle size, and microscopic records were also taken. Since barley blended with water produced an emulsion, it seemed that after 45 seconds of blending the emulsion became saturated with solutes. Principal component analysis (PCA) was used to investigate if it was possible to classify the samples [20] and distinguish them (barley milk from barley spent and grain) just using the NIR spectra (Figure 2). The distribution patterns depended on whether the sample is milk or mash remaining after blending. The starting sample, barley grain, was positioned between the 1st and 2nd quadrants, which indicated that parts of the grain could be found in the milk (positioned in the third quadrant) and the remaining spent grain after blending. The samples were separated more or less according to the blending time. The remaining barley grain, despite the different particle size, was grouped very closely in the 4 th quadrant. Samples that were blended 45 and 60 seconds were closely positioned to the axis showing that in those samples of barley milk the composition was very similar to that of the barley grain which was positioned on the same axis (Figure 2).

The presented principal component analysis of the sample distribution followed the trend of the presented spectra (Figures 1(a) and 1(b)) where the sample M_45 s had lower AU than the sample M_60 s, and therefore the sample (M_45s) was positioned in the fourth quadrant. The Graph Data Editor in the Statistica software package showed the Scatterplot $X$ value(s) for all the observed samples and for the barley spent grain samples the $X$ values ranged from 19.7 to 24.6, while the sample of barley based milk that was blended for 45 seconds is outlined just for the value 4.3. This is the argument, why this sample (M_45s) should be in the group "barley milk," but to investigate if there are maybe other reasons for such positioning of the samples, further analysis of the samples was conducted (particle size and conductivity).

3.2. Particle Size Distribution. By definition, bovine and grain milks are both colloidal emulsions and suspensions, that is,

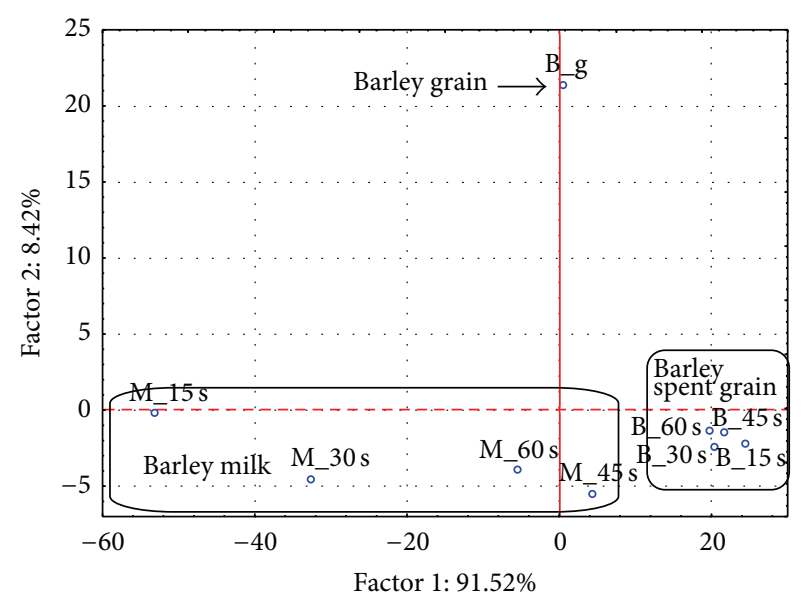

FIGURE 2: Principal component analysis of NIR absorbance spectra for barley grain (B_g), barley milk $(M)$, and spent barley grain (B) after 15, 30, 45, and 60 seconds of blending.

dispersions in which there are particles or droplets with at least one linear dimension in the size range of $1 \mathrm{~nm}$ to about $1 \mu \mathrm{m}$ [6]. Volume particle size distributions of both barley milk and spent barley grain are shown in Figures 3 and 4 .

Figure 3 shows particle size distribution (by volume) of barley based milk samples. Bimodal distribution was visible for all barley milk samples, with the first peak visible at approximately $25 \mu \mathrm{m}$, which corresponded to the size of fat droplets present in the emulsion. Volume percentage of these particles was the smallest for the barley milk sample blended for 60 seconds, which indicated that at this duration of the blending process, particles tend to form larger aggregates. The second peak ranged from 100 to $300 \mu \mathrm{m}$ and corresponded to larger plant structure particles present in the sample and particle aggregates. The presence of larger particles was more pronounced in samples with longer blending time, which was also an indication that the blending process which lasted for a too long period of time could result in unwanted 
TABLE 1: Mean diameter $(d(0.5))$, Sauter diameter $(D[3,2])$, and specific surface area of barley based milk. Results are expressed as mean of 3 measurements \pm SD $^{*}$.

\begin{tabular}{|c|c|c|c|}
\hline Barley milk sample & $d(0.5)[\mu \mathrm{m}]$ & $D[3,2][\mu \mathrm{m}]$ & Specific surface area $\left[\mathrm{m}^{2} \mathrm{~g}^{-1}\right]$ \\
\hline M_15 s & $26.40 \pm 2.67^{\mathrm{a}}$ & $10.01 \pm 0.68^{\mathrm{a}}$ & $0.60 \pm 0.04^{\mathrm{a}}$ \\
\hline M_30 s & $23.93 \pm 0.71^{\mathrm{a}}$ & $9.25 \pm 0.20^{\mathrm{b}}$ & $0.65 \pm 0.01^{\mathrm{a}}$ \\
\hline M_45 s & $26.67 \pm 0.92^{\mathrm{b}}$ & $11.38 \pm 0.27^{c}$ & $0.53 \pm 0.01^{\mathrm{b}}$ \\
\hline M_60 s & $40.44 \pm 1.90^{\mathrm{b}}$ & $13.55 \pm 2.00^{\mathrm{d}}$ & $0.44 \pm 0.01^{\mathrm{b}}$ \\
\hline
\end{tabular}

*Values in the same column with different letters are significantly different (Duncan, $p<0.05$ ).

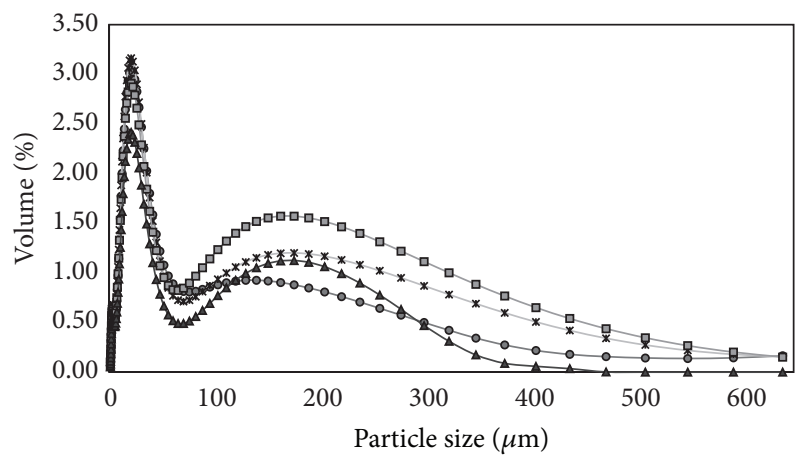

$\rightarrow$ Milk 15s (M_15s) $\quad$ * Milk 30s (M_30s)

$\rightarrow$ Milk 45s (M_45s) $\rightarrow$ Milk60s (M_60s)

FIgURE 3: Particle size distribution of barley milk.

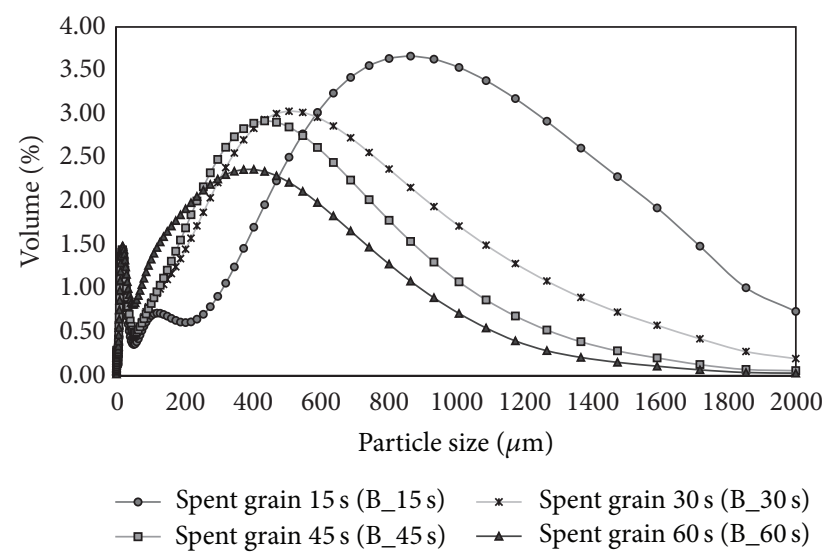

FIgURe 4: Particle size distribution of spent barley grain used to make barley milk.

behaviour of the barley based milk emulsion. Furthermore, the percentage of very large particles with diameters above 300 and $400 \mu \mathrm{m}$ corresponding to cellular material was the largest in samples blended for 30 and 45 seconds, which could be explained by the longer homogenisation of the product, which, when sampled, contained all particle types present in the mixture. Interestingly, the same observation could not be made for barley milk sample blended for 60 seconds, which meant that longer blending time resulted in disruption of the cellular material to very small particles, but, at the same time, destabilised the emulsion by forming droplet aggregates.
Particle size distribution of barley spent grain left over after barley milk production is shown in Figure 4. Although the barley spent grain was separated from the barley milk through a gauze, particle size distribution showed the presence of a small amount of droplets with particle sizes around $25 \mu \mathrm{m}$. The distribution was also bimodal, and the shift of the second peak towards larger particle diameters was visible for samples with lower blending time, for example, maximum value of about $900 \mu \mathrm{m}$ for sample blended for 15 seconds, $500 \mu \mathrm{m}$ for sample blended for 30 seconds, around $400 \mu \mathrm{m}$ for sample blended for 45 seconds, and approximately $375 \mu \mathrm{m}$ for sample blended for 60 seconds. The greatest difference in particle size was observed between samples blended for 15 and 60 seconds, while the particle size distribution curves were similar for samples blended for 30 and 45 seconds. Although particle size distribution gives a reliable insight in the state of the tested samples, either solid or liquid, in some cases particle size is characterized by one or two particle size parameters, which are usually easier to interpret than the complete distribution, but they very often omit some important details about the samples. Standard parameters used to simplify particle size distribution often include percentile values such as median diameter $(d(0.5))$ which represents a diameter below $50 \%$ of particles lie and Sauter diameter (surface to volume ratio) which is useful in cases where it is important to know how the particle reacts to its surroundings [21]. Table 1 shows the values of $d(0.5), D[3,2]$ and specific surface area of the barley based milk.

As seen in Table 2, particle size diameters of samples blended for 15 (M_15 s) and 30 (M_30 s) seconds did not show significant differences. However, barley milk sample blended for 60 seconds (M_60 s) differed significantly from other samples with higher median and Sauter diameter values. This was an indication of possible formation of particle aggregates which made the emulsion less stable in comparison to those blended for a shorter time period. Consequently, larger aggregates formed particles with smaller specific surface area.

Opposed to barley milk samples, spent grain separated after barley milk production exhibited properties in accordance with literature data: longer blending time resulted in smaller particles which had larger surface area (Table 2). Once again, only small differences were visible between samples blended for 45 and 60 seconds, which was an indicator that 45 seconds could be the optimal blending time.

3.3. Electrical Conductivity. To investigate the necessity of 15 seconds of more blending that is time and energy consuming, other methods were used to confirm which of the plant 
TABLE 2: Particle size parameters of spent grain used for barley milk production. Results are expressed as mean of 3 measurements \pm SD*

\begin{tabular}{|c|c|c|c|}
\hline Spent barley grain sample & $d(0.5)$ & $D[3,2]$ & Specific surface area $\left[\mathrm{m}^{2} \mathrm{~g}^{-1}\right]$ \\
\hline B_15 s & $509.28 \pm 35.06^{\mathrm{a}}$ & $34.97 \pm 1.84^{\mathrm{a}}$ & $0.17 \pm 0.01^{\mathrm{a}}$ \\
\hline B_30 s & $286.76 \pm 11.41^{\mathrm{b}}$ & $30.39 \pm 0.97^{\mathrm{b}}$ & $0.20 \pm 0.01^{\mathrm{b}}$ \\
\hline B_45 s & $218.40 \pm 10.99^{c}$ & $26.43 \pm 1.33^{\mathrm{c}}$ & $0.23 \pm 0.01^{c}$ \\
\hline B_60 s & $144.55 \pm 13.31^{\mathrm{d}}$ & $25.70 \pm 0.97^{\mathrm{d}}$ & $0.23 \pm 0.01^{c}$ \\
\hline
\end{tabular}

${ }^{*}$ Values in the same column with different letters are significantly different (Duncan, $p<0.05$ ).

based milk is good enough. A useful tool that effectively elucidates the microstructural changes of self-assembled colloidal systems is the electrical conductivity that can be used to obtain important information concerning the phase transition which occurs in microemulsions systems [22, 23]. Electrical conductivity sensors are used to measure the ability of water to carry an electrical current. Absolutely pure water is a poor conductor of electricity. Water shows significant conductivity when dissolved salts are present. Over most ranges, the amount of conductivity is directly proportional to the amount of salts dissolved in the water. The amount of mineral and salt impurities in the water presents the total dissolved solids (TDS). TDS is measured in parts per million showing how many units of impurities there are for one million units of water. This measures the "impurities" in water that is now barley milk.

Latreille and Paqin [24] have applied the conductivity measurements to evaluate the emulsion stability using concentrated milk-based liquid infant formula as emulsions. Their results have outputted an increase of conductivity as a function of time due to creaming of fat globules. These globules are nonconductors with respect to the water-protein mixture which, on the other hand, is a good conductor [25].

Our finding confirmed the increase of conductivity as a function of time (Figure 5) showing the saturation of the emulsion with the measured total dissolved solids in the planbased milks observed on samples of barley milk blended for longer than 45 seconds. The trend of tested significance was the same for the observed electrical conductivity and for the total dissolved solids of the samples blended for a different period of time (Figure 5). No significant difference was detected for the electrical conductivity and for the total dissolved solids for barley based milk after 45 versus 60 seconds.

3.4. Light Microscopy. Light microscopy was performed to get an insight into the structures of the particles present in the barley milk samples. Micrographs are shown in Figure 6.

Light microscope images (Figure 6) confirmed results of laser diffraction particle size analysis. The smallest particles in all samples, visible as slightly yellow droplets, represent fat droplets and are approximately $25 \mu \mathrm{m}$ in diameter. These droplets are well dispersed in the sample blended for 15 seconds (Figure 6(a)), while aggregates of the droplets are present in samples blended for 30 (Figure 6(b)), 45 (Figure 6(c)), and 60 seconds (Figure 6(d)). Lager particles

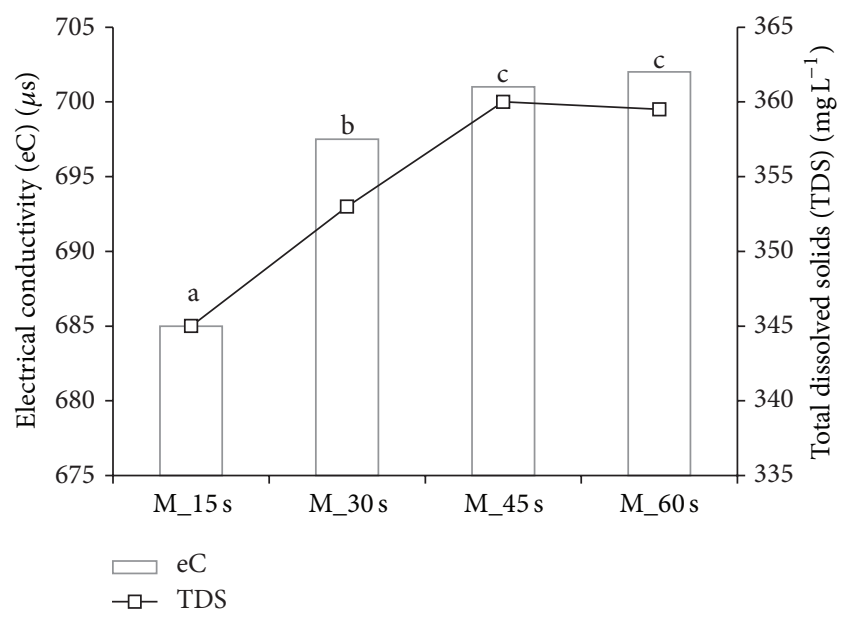

FIGURE 5: Electrical conductivity $(\mathrm{eC})$ and total dissolved solids (TDS) of barley milk (M) after 15, 30, 45, and 60 seconds of blending. Means with different letters are significantly different $(p<0.05)$.

of plant material are also visible, as well as the air entrapped between the particles.

\section{Conclusions}

Presented results demonstrated that an emulsion such as barley milk and barley spent grain can be identified and distinguished when the principal component analysis was applied on absorbance NIR spectra. Results also showed that the emulsion saturation can be determined by measuring electrical conductivity combined with total dissolved solids indicating the stability of water-protein mixture.

Based on all findings, the optimal blending time in the plant based milk production (in the case of barley) would be 45 seconds because the total dissolved solids as the qualitative indicator of the emulsion showed saturation. This was further confirmed with the NIR measurements particle size and microscopy analysis. In the industrial production process those findings would result in saved time and energy.

\section{Abbreviations}

B_g: Barley (as grain)

B: Barley spent grain (after blending)

M: Barley based milk. 


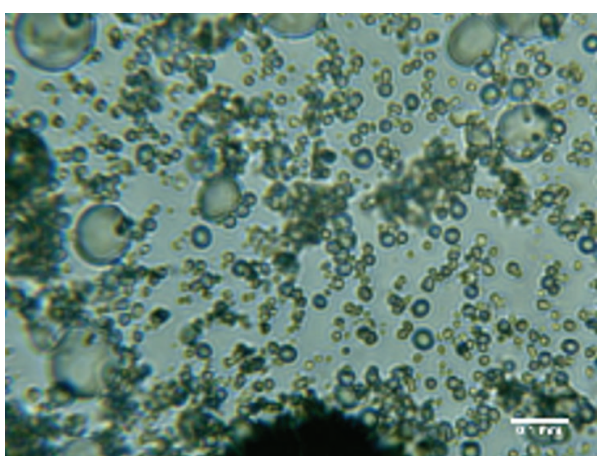

(a)

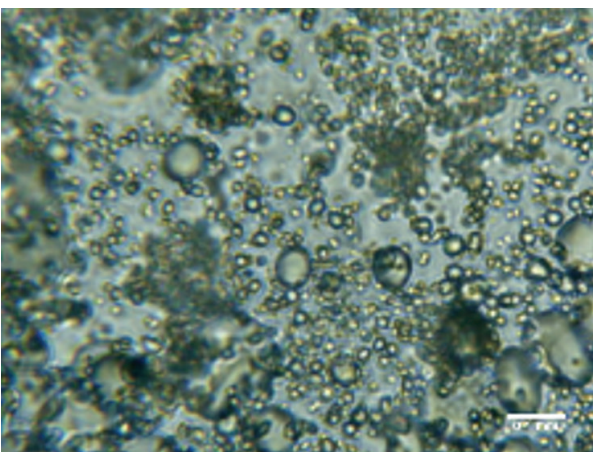

(c)

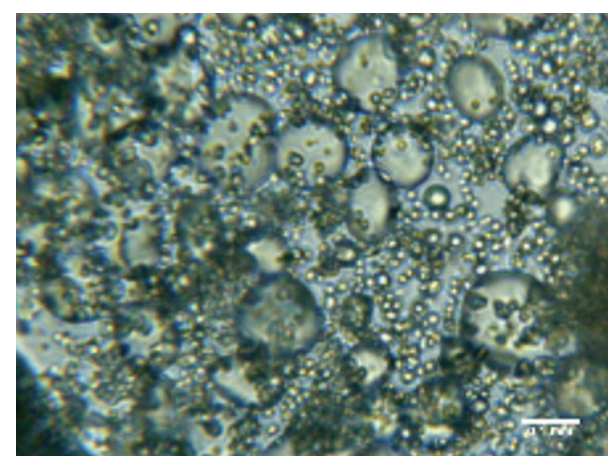

(b)

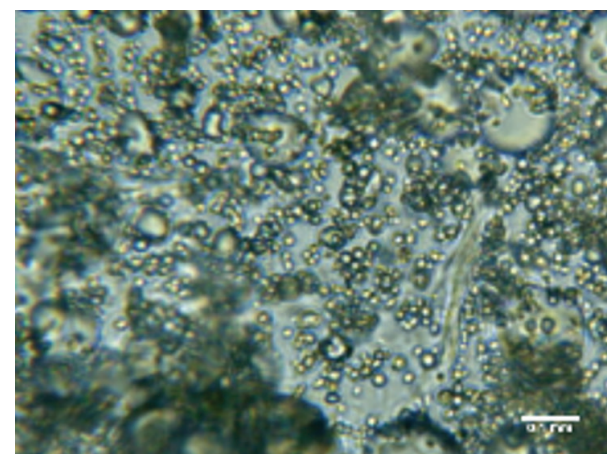

(d)

Figure 6: Microscope photographs of barley milk samples blended for (a) 15 seconds; (b) 30 seconds; (c) 45 seconds; and (d) 60 seconds (line is $0.1 \mathrm{~mm}$ ).

\section{Conflict of Interests}

The authors declare that there is no conflict of interests regarding the publication of this paper.

\section{References}

[1] E. Arendt and E. Zanini, "Barley," in Cereal Grains for the Food and Beverage Industries, pp. 155-200, Woodhead Publishing, Woodhead, UK, 2013.

[2] B.-K. Baik and S. E. Ullrich, "Barley for food: characteristics, improvement, and renewed interest," Journal of Cereal Science, vol. 48, no. 2, pp. 233-242, 2008.

[3] M. Havrlentova, Z. Petrulakova, A. Burgarova, F. Gago, A. Hlinkova, and E. Šturdik, "Cereal $\beta$-glucans and their significance for the preparation of functional foods-a review," Czech Journal of Food Sciences, vol. 29, no. 1, pp. 1-14, 2011.

[4] C. W. Newman and R. K. Newman, "A brief history of barley foods," Cereal Foods World, vol. 51, no. 1, pp. 4-7, 2006.

[5] O. E. Mäkinen, V. Wanhalinna, E. Zannini, and E. K. Arendt, "Foods for special dietary needs: non-dairy plant based milk substitutes and fermented dairy type products," Critical Reviews in Food Science and Nutrition, 2015.

[6] A. Durand, G. V. Franks, and R. W. Hosken, "Particle sizes and stability of UHT bovine, cereal and grain milks," Food Hydrocolloids, vol. 17, no. 5, pp. 671-678, 2003.

[7] O. E. Mäkinen, T. Uniacke-Lowe, J. A. O’Mahony, and E. K. Arendt, "Physicochemical and acid gelation properties of commercial UHT-treated plant-based milk substitutes and lactose free bovine milk," Food Chemistry, vol. 168, pp. 630-638, 2015.
[8] B. Aernouts, R. van Beers, R. Watté et al., "Effect of ultrasonic homogenization on the Vis/NIR bulk optical properties of milk," Colloids and Surfaces B: Biointerfaces, vol. 126, pp. 510519, 2015.

[9] B. Aernouts, E. Polshin, J. Lammertyn, and W. Saeys, "Visible and near-infrared spectroscopic analysis of raw milk for cow health monitoring: reflectance or transmittance?" Journal of Dairy Science, vol. 94, no. 11, pp. 5315-5329, 2011.

[10] A. Bogomolov and A. Melenteva, "Scatter-based quantitative spectroscopic analysis of milk fat and total protein in the region $400-1100 \mathrm{~nm}$ in the presence of fat globule size variability," Chemometrics and Intelligent Laboratory Systems, vol. 126, pp. 129-139, 2013.

[11] B. M. Nicolaï, K. Beullens, E. Bobelyn et al., "Nondestructive measurement of fruit and vegetable quality by means of NIR spectroscopy: a review," Postharvest Biology and Technology, vol. 46, no. 2, pp. 99-118, 2007.

[12] I. Budić-Leto, J. Gajdoš-Klusurić, G. Zdunić et al., "Usefulness of near infrared spectroscopy and chemometrics in screening of the quality of dessert wine Prošek," Croatian Journal of Food Science and Technology, vol. 3, no. 2, pp. 9-15, 2011.

[13] Ž. Kurtanjek and J. G. Kljusurić, "Statistical modelling of anthropometric characteristics evaluated on nutritional status," in Mathematical and Statistical Methods in Food Science and Technology, John Wiley \& Sons, London, UK, 2014.

[14] R. K. Gupta, S. S. Gangoliya, and N. K. Singh, "Reduction of phytic acid and enhancement of bioavailable micronutrients in food grains," Journal of Food Science and Technology, vol. 52, no. 2, pp. 676-684, 2015. 
[15] J. A. Han and S. T. Lim, "Effect of presoaking on textural, thermal, and digestive properties of cooked brown rice," Cereal Chemistry, vol. 86, no. 1, pp. 100-105, 2009.

[16] L. S. Magwaza, U. L. Opara, P. J. R. Cronje et al., "Assessment of rind quality of 'Nules Clementine' mandarin fruit during postharvest storage: 2 . Robust Vis/NIRS PLS models for prediction of physico-chemical attributes," Scientia Horticulturae, vol. 165, pp. 421-432, 2014.

[17] M. Golic, K. Walsh, and P. Lawson, "Short-wavelength nearinfrared spectra of sucrose, glucose, and fructose with respect to sugar concentration and temperature," Applied Spectroscopy, vol. 57, no. 2, pp. 139-145, 2003.

[18] S. Kawano, T. Fujiwara, and M. Iwamoto, "Non-destructive determination of sugar content in 'Satsuma' mandarins using NIRS transmittance," Journal of the Japanese Society for Horticultural Science, vol. 62, pp. 465-470, 1993.

[19] J. C. Tewari, V. Dixit, B.-K. Cho, and K. A. Malik, "Determination of origin and sugars of citrus fruits using genetic algorithm, correspondence analysis and partial least square combined with fiber optic NIR spectroscopy," Spectrochimica Acta A: Molecular and Biomolecular Spectroscopy, vol. 71, no. 3, pp. 1119-1127, 2008.

[20] A. Grané and A. Jach, "Applications of principal component analysis (PCA) in food science and technology," in Mathematical and Statistical Methods in Food Science and Technology, D. Granato and G. Ares, Eds., John Wiley \& Sons, Chichester, UK, 2014.

[21] T. Allen, Particle Size Measurement: Volume 1-Powder Sampling and Particle Size Measurement, Chapman and Hall, London, UK, 5th edition, 1997.

[22] H. Zhang, M. Taxipalati, F. Que, and F. Feng, "Microstructure characterization of a food-grade U-type microemulsion system by differential scanning calorimetry and electrical conductivity techniques," Food Chemistry, vol. 141, no. 3, pp. 3050-3055, 2013.

[23] A. Yaghmur, A. Aserin, B. Antalek, and N. Garti, "Microstructure considerations of new five-component Winsor IV foodgrade microemulsions studied by pulsed gradient spin-echo NMR, conductivity, and viscosity," Langmuir, vol. 19, no. 4, pp. 1063-1068, 2003.

[24] B. Latreille and P. Paqin, "Evaluation of emulsion stability by centrifugation with conductivity measurements," Journal of Food Science, vol. 55, no. 6, pp. 1666-1668, 1990.

[25] N. B. Webb, F. J. Ivey, H. B. Craig, V. A. Jones, and R. J. Monroe, "The measurement of emulsifying capacity by electrical resistance," Journal of Food Science, vol. 35, no. 4, pp. 501-504, 1970. 

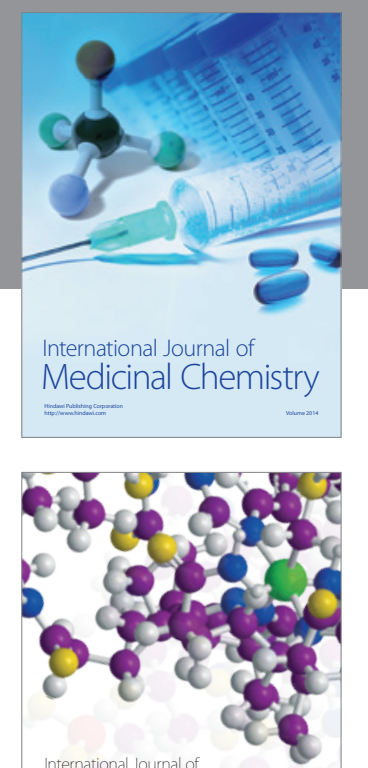

\section{Carbohydrate} Chemistry

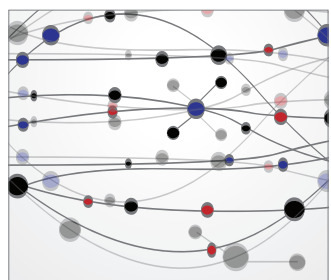

The Scientific World Journal
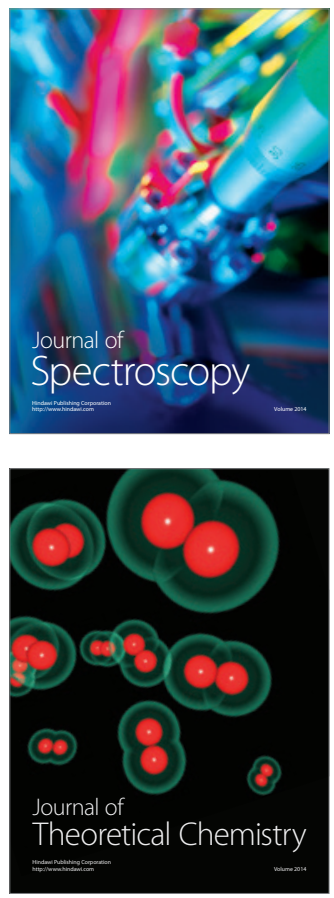
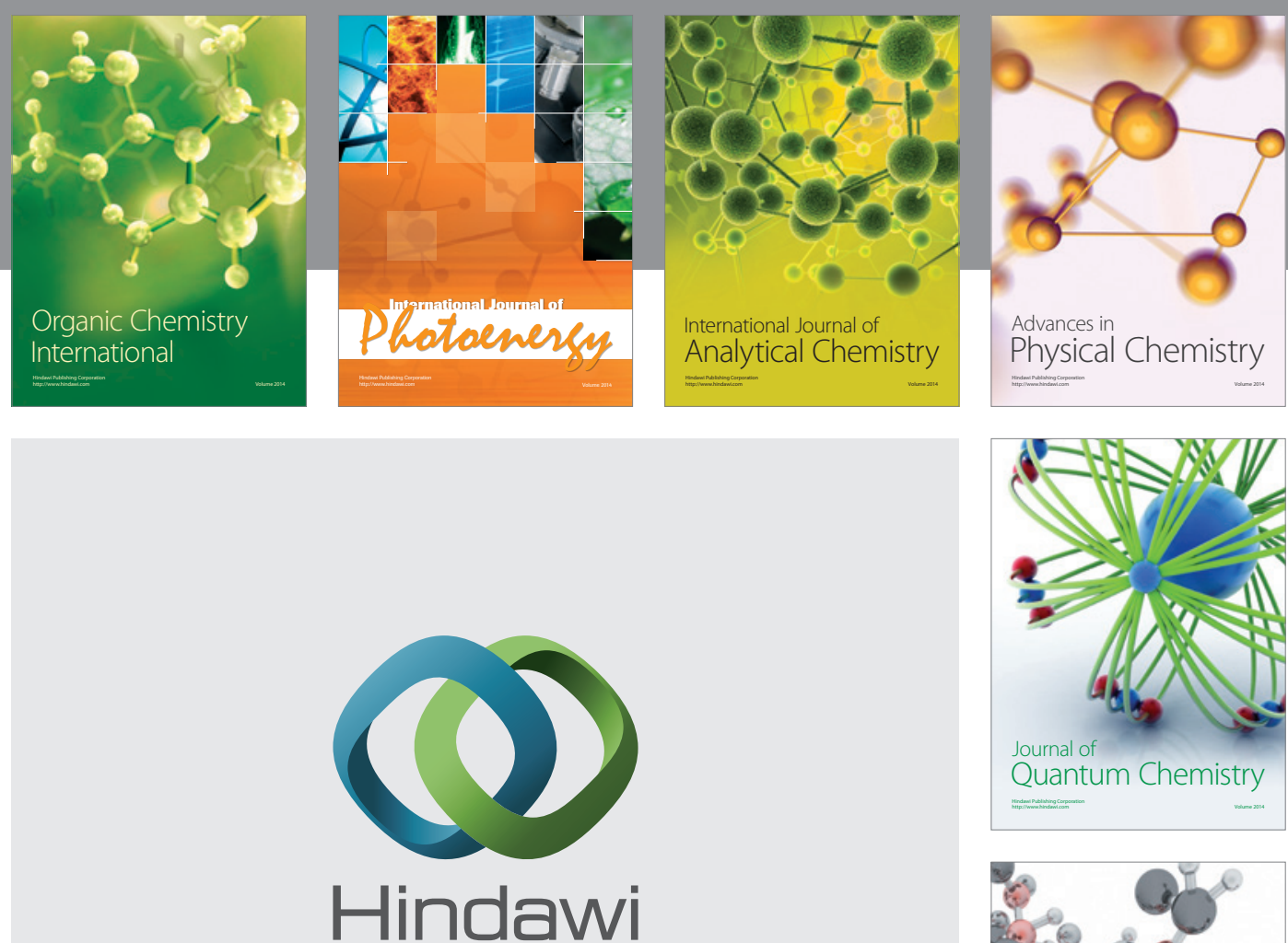

Submit your manuscripts at

http://www.hindawi.com

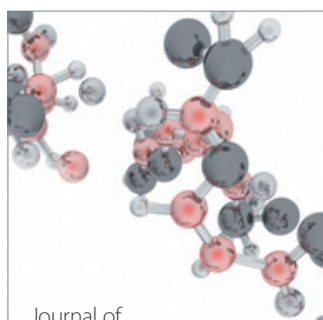

Analytical Methods

in Chemistry

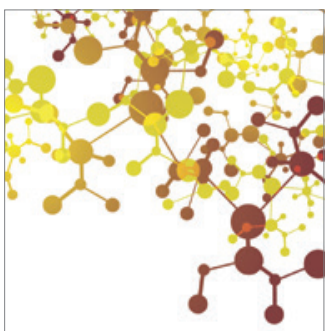

Journal of

Applied Chemistry

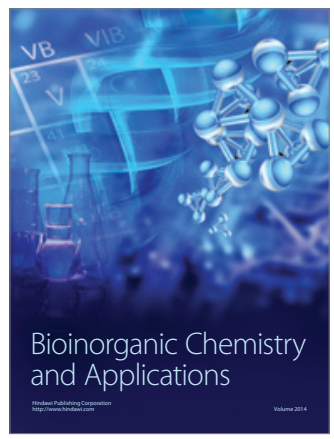

Inorganic Chemistry
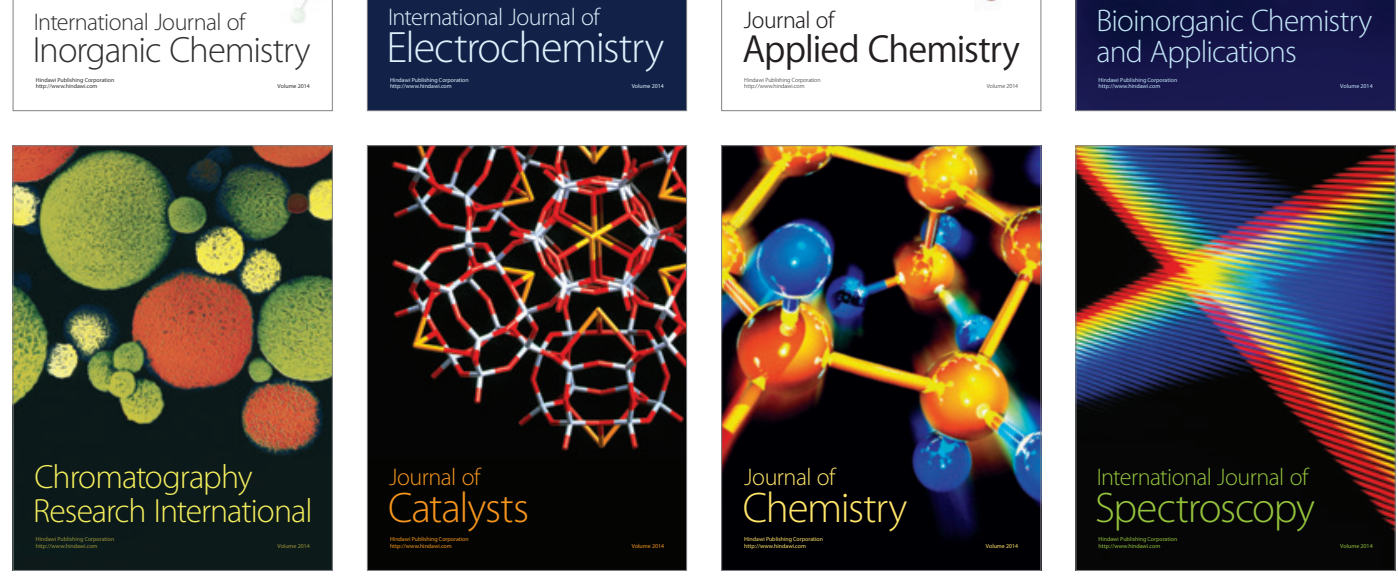